\title{
Análise do Discurso de Gênero no Contexto Hospitalar: Perspectivas de Mulheres Internadas nas Enfermarias de Ginecologia e Obstetrícia
}

\author{
Juliana Machado Ruiz ${ }^{1}$ \\ Rafael De Tilio ${ }^{1}$ \\ ${ }^{1}$ Universidade Federal do Triângulo Mineiro, MG, Brasil. $\quad{ }^{1}$ Universidade Federal do Triângulo Mineiro, MG, Brasil.
}

\begin{abstract}
Resumo: O objetivo desta pesquisa foi compreender as formações discursivas (FD) de gênero relativas aos cuidados em saúde de mulheres internadas nas enfermarias de ginecologia/ obstetrícia de um hospital. Participaram do estudo treze mulheres e os dados foram analisados a partir da análise do discurso de Michel Pêcheux. As principais FD identificadas destacaram a naturalização da forma como as mulheres devem se relacionar com o sistema de saúde por meio do que é tradicionalmente delegado a esse gênero (mãe e cuidadora), priorizando intervenções voltadas para a saúde reprodutiva, bem como a matriz hegemônica do modelo biomédico na organização desses serviços, distanciando-os dos modelos de integralidade propostos pelas políticas públicas em saúde voltadas para esse público. Considerou-se o campo da saúde enquanto espaço discursivo de (re)produção de estereótipos e desigualdades de gênero, alicerçado em formações ideológicas e imaginárias que são constituintes dos modos como os sujeitos transitam nesse cenário. Propõem-se a compreensão das questões de gênero como conteúdo transversal a todas as áreas e contextos de saúde, partindo da perspectiva de que um melhor entendimento do universo feminino em relação à saúde, alicerçado pelas questões de gênero, pode favorecer a oferta de programas e serviços condizentes com as reais demandas e necessidades dessa população.
\end{abstract}

Palavras-chave: Gênero, Saúde, Hospital, Análise do Discurso.

\section{Discourse Analysis of Gender in the Hospital Context: Perspectives of Women Hospitalized in Gynecology and Obstetrics Wards}

\begin{abstract}
This study aimed to understand the Discursive Formations about gender related to health care of women hospitalized in gynecology and obstetrics wards in a hospital. Thirteen women participated in this study and their interviews were analyzed in the light of Michel Pêcheux discourse analysis. The main Discursive Formations identified showed the naturalization of the way women should relate to the health system based on what is traditionally delegated to this gender (mother and caregiver), prioritizing reproductive health interventions, and the hegemonic matrix of the biomedical model in the organization of these services, pushing them away from the models of integrality proposed in public health policies. The health system was considered a discursive space for (re)production of gender stereotypes and inequalities based on Ideological and Imaginary Formations that are constituents of the ways in which these subjects relate in this scenario. It is proposed to understand gender issues as a crosscutting content in all health areas and contexts, starting from the perspective that a better understanding of the female universe regarding health care, based on gender issues, can improve the offer of programs and services more consistent with the real demands and needs of this population.
\end{abstract}

Keywords: Gender, Health, Hospital, Discourse Analysis. 


\title{
Análisis del Discurso de Género en el Contexto Hospitalario: Perspectivas de Mujeres Internadas en las Enfermerías de Ginecología y Obstetrician
}

\begin{abstract}
Resumen: El objetivo de esta investigación fue comprender las formaciones discursivas (FD) de género relacionadas a la atención en salud de mujeres internadas en las enfermerías de ginecología/obstetricia en una institución hospitalaria. Participaron en el estudio trece mujeres, y se aplicó a los datos recopilados el análisis del discurso de Michel Pêcheux. Las principales FD identificadas destacaron la naturalización de la forma en que las mujeres deben relacionarse con el sistema de salud mediante lo que es tradicionalmente delegado a ese género (madre y cuidadora), priorizando intervenciones dirigidas a la salud reproductiva, así como la matriz hegemónica del modelo biomédico en la organización de esos servicios, distanciándolos de los modelos de integralidad propuestos en las políticas públicas en salud dirigidas a ese público. Se consideró el campo de la salud como espacio discursivo de (re)producción de estereotipos y desigualdades de género basado en formaciones ideológicas e imaginarias que son constituyentes de los modos como los sujetos transitan en ese escenario. Se propone la comprensión de las cuestiones de género como contenido transversal a todas las áreas y contextos de salud, partiendo de la perspectiva de que un mejor entendimiento del universo femenino en relación a la salud, basada en las cuestiones de género, puede favorecer la oferta de programas y servicios condicionados con las reales demandas y necesidades de esa población.
\end{abstract}

Palabras clave: Género, Salud, Hospital, Análisis del discurso.

O campo social enquanto espaço de construção e (re)produção das relações desiguais entre os gêneros constitui os sujeitos pela interpelação de diferentes discursos, representações e práticas. Desse modo, tanto as instituições como as práticas são generificadas, visto que são constituídas e também constituintes de gêneros (Louro, 2003). Assim, as relações de gênero - compreendidas como construções sociais e como práticas veiculadas por sujeitos sócio-históricos (Butler, 2015) - imersas em contextos políticos específicos ocupam diferentes cenários, dentre eles os serviços de saúde.

É importante considerar que a Psicologia, enquanto dedicada, dentre outros, à prevenção de doenças e agravos, à promoção da saúde e ao tratamento/ redução de danos ou de sofrimentos, possui interfaces com a Saúde Coletiva (Osmo \& Schraiber, 2015) e, assim, se preocupa com os impactos dos determinantes sociais de saúde (DSS) ${ }^{1}$ na qualidade de vida e no bem-estar dos sujeitos e das coletividades. Dentre os DSS estão as identidades de gênero - $\mathrm{e}$ as orientações sexuais
(Silva, Paulino, \& Raimondi, 2020) - que impactam as condições de saúde e que, por isso, necessitam de atenção e de intervenção especializadas visando a resolubilidade e a integralidade do cuidado em saúde e do enfretamento dos agravos (Alves, 2018; Conselho Federal de Psicologia, 2019; Martin, Montanari, Pereira, Hamburguer, \& Silveira, 2018).

Por isso o gênero é um dos elementos interseccionais da saúde e deve ser compreendido como histórica e socialmente constituído e, assim como a saúde, não pode ser reduzido aos fatores biológicos dos corpos - gênero não se confunde com sexo (Butler, 2015) e saúde não se limita à ausência de doenças (Araújo, Schraiber, \& Cohen, 2011). As determinações e relações de gênero estabelecem desigualdades entre os sujeitos em diversas áreas, inclusive na saúde (Couto \& Dantas, 2016; Motta, 2016; Sen, George, \& Östlin, 2002).

O conceito de gênero não está pacificado na literatura científica. Nesta pesquisa, optou-se pela definição de gênero da argumentação de Butler (2015) sobre o gênero (e as desigualdades sociais dele resultante)

${ }^{1}$ Os DDS são fatores (sociais, econômicos, culturais, psicológicos e comportamentais) que influenciam a ocorrência de problemas/ agravos de saúde e os fatores de risco/vulnerabilidade destes nas populações. 
como relações socialmente construídas, e não como resultado da biologia dos corpos. No contexto da saúde coletiva, os estudos sobre gênero vêm se mostrando importantes para compreender vários aspectos, dentre os quais: os processos de construção das identidades femininas e masculinas, a forma como os sujeitos aderem aos serviços de saúde e as práticas de autocuidado (Aquino, 2006; Marques, 2010; Schraiber, 2012; Villela, Monteiro, \& Vargas, 2009); além destes, a atuação dos profissionais de saúde e as práticas assistenciais oferecidas pelas instituições e serviços de saúde (Machin et al., 2011; Motta, 2016; Toneli, Souza, \& Müller, 2010). Portanto gênero deve ser considerado elemento estruturante dos programas de saúde e das práticas profissionais e sociais. Assim, Machin et al. (2011) e Schraiber (2012) destacam o campo da saúde como palco privilegiado para a manifestação e (re)produção de possíveis desigualdades e estereótipos de gênero.

Daí a urgência de discutir e retomar a historicidade dos processos de constituição subjetiva nos espaços de saúde. Isso permite uma análise contextualizada desse campo e, quiçá, mudanças visando uma assistência integral às demandas dos sujeitos (Schraiber, 2012). Éimprescindível o reconhecimento do gênero enquanto um dos DSS, sendo importante sua inclusão tanto no planejamento como na formulação de políticas públicas do Sistema Único de Saúde (SUS).

A respeito do SUS, a integralidade (um dos seus princípios norteadores) necessita de ações e programas que incluam os DSS nas práticas de atenção e cuidados em saúde (Bedrikow \& Campos, 2011), tal como no caso a Política Nacional de Atenção Integral à
Saúde da Mulher (PNAISM) (Brasil, 2004). Em relação ao público feminino, entende-se que as desigualdades de gênero (características de uma sociedade patriarcal, violenta, misoginia, com sobrecarga de trabalho das mulheres etc.) colocam as mulheres em situação de vulnerabilidade em saúde. No entanto esses aspectos não são plenamente considerados pelas políticas públicas (Souto, 2008; Souza, Peres, \& Araújo, 2015).

A partir do exposto, considera-se que investigações que articulem gênero e saúde da mulher sejam importantes, a fim de ampliar a compreensão sobre como essas relações se constituem e distribuem consequências para as usuárias do SUS. Esse artigo tem como objetivo compreender as formações discursivas de gênero relativas aos cuidados em saúde de mulheres internadas nas enfermarias de ginecologia/ obstetrícia em uma instituição hospitalar.

\section{Método}

Trata-se de um estudo exploratório, de caráter qualitativo e de corte transversal. Participaram treze mulheres internadas nas enfermarias de ginecologia e obstetrícia do Hospital de Clínicas da Universidade Federal do Triângulo Mineiro (HC-UFTM) em Uberaba (MG). Todas tinham mais de 18 anos de idade. Não houve restrições quanto ao diagnóstico de internação e foram excluídas as que não estavam internadas nas enfermarias especificadas ou que estavam impossibilitadas de responder à entrevista por restrições médicas. O Quadro 1 apresenta as principais características das participantes (nome fictício, idade, estado civil, profissão, escolaridade, número de filhos, renda individual e familiar).

\section{Quadro 1}

Caracterização das participantes (nome fictício, idade, estado civil, profissão, escolaridade, número de filhos, renda individual e familiar).

\begin{tabular}{|c|c|c|c|c|c|c|}
\hline $\begin{array}{l}\text { Nome } \\
\text { Fictício }\end{array}$ & Idade & Estado Civil & Profissão & Escolaridade & $\begin{array}{l}\mathrm{N}^{\circ} \text { de } \\
\text { Filhos }\end{array}$ & $\begin{array}{c}\text { Renda (R\$) } \\
\text { Individual/Familiar }\end{array}$ \\
\hline Elena & 29 & Casada & Do lar & Médio completo & 3 & $0 / 4.000$ \\
\hline Sofia & 18 & Solteira & Desempregada & Médio incompleto & 1 & $0 / 5.000$ \\
\hline Alice & 33 & Casada & Do lar & $\begin{array}{l}\text { Fundamental } \\
\text { incompleto }\end{array}$ & 2 & $0 / 1.800$ \\
\hline Jéssica & 32 & Amasiada & Do lar & Médio incompleto & 2 & $0 / 1.600$ \\
\hline Edna & 48 & Divorciada & $\begin{array}{l}\text { Trabalhadora } \\
\text { rural }\end{array}$ & Superior incompleto & 2 & 2.500 \\
\hline
\end{tabular}




\begin{tabular}{|c|c|c|c|c|c|c|}
\hline $\begin{array}{l}\text { Nome } \\
\text { Fictício }\end{array}$ & Idade & Estado Civil & Profissão & Escolaridade & $\begin{array}{l}\text { No de } \\
\text { Filhos }\end{array}$ & $\begin{array}{c}\text { Renda }(\mathrm{R} \$) \\
\text { Individual/Familiar }\end{array}$ \\
\hline Amanda & 25 & Casada & Do lar & Médio completo & 1 & $0 / 2.800$ \\
\hline Iris & 24 & Casada & Do lar & $\begin{array}{l}\text { Fundamental } \\
\text { incompleto }\end{array}$ & 1 & $0 / 2.000$ \\
\hline Ângela & 18 & Solteira & Estudante & Médio incompleto & 1 & - \\
\hline $\begin{array}{c}\text { Ana } \\
\text { Carolina }\end{array}$ & 27 & Amasiada & $\begin{array}{c}\text { Trabalhadora } \\
\text { rural }\end{array}$ & $\begin{array}{l}\text { Fundamental } \\
\text { incompleto }\end{array}$ & 3 & $250 / 1.000$ \\
\hline Carina & 28 & Amasiada & Vendedora & Médio completo & 2 & $1.116 / 2.700$ \\
\hline Vitória & 18 & Amasiada & $\begin{array}{l}\text { Dama de } \\
\text { companhia }\end{array}$ & $\begin{array}{l}\text { Fundamental } \\
\text { incompleto }\end{array}$ & 1 & $800 / 2.400$ \\
\hline Clarice & 31 & Casada & $\begin{array}{l}\text { Cuidadora de } \\
\text { idoso }\end{array}$ & Médio completo & 3 & $900 / 4.000$ \\
\hline Marcela & 34 & Casada & Professora & Superior completo & 1 & $1.200 / 8.000$ \\
\hline
\end{tabular}

O cenário de pesquisa foi o HC-UFTM, que atende 27 municípios que compõem a macrorregião Triângulo Sul do estado de Minas Gerais. É o único hospital na região que oferece atendimento de alta complexidade e a totalidade da sua demanda é atendida pelo SUS, com 302 leitos ativos, sendo 13 de enfermaria de ginecologia e 22 de obstetrícia.

Para a coleta de dados utilizou-se como instrumento um roteiro de entrevista semiestruturado formulado pelos pesquisadores. As questões foram divididas em quatro eixos: caracterização das participantes; concepções sobre saúde; informações sobre a internação; e percepção sobre os cuidados oferecidos pelos profissionais e serviços de saúde.

Como procedimentos de coleta de dados, inicialmente, foi feita a notificação aos médicos responsáveis pelos setores sobre o início da coleta de dados. Quanto às participantes, realizou-se contato direto nas respectivas enfermarias. Após esclarecimentos sobre os objetivos da pesquisa e aceite/assinatura do Termo de Consentimento Livre e Esclarecido (TCLE), a coleta de dados foi feita individualmente em datas e horários em que as participantes se dispuseram. A critério das participantes, as entrevistas foram realizadas numa sala reservada para atendimentos familiares do HC-UFTM ou beira-leito, tomando os devidos cuidados para resguardo do sigilo das informações da identidade das participantes. As entrevistas foram transcritas na íntegra (os nomes foram substituídos por fictícios) e realizou-se a análise com base no referencial teórico da análise do discurso (AD) de Michel Pêcheux.

Procedimentos de análise dos dados: a $\mathrm{AD}$ de Michel Pêcheux tem como objeto de estudo o discurso, definido como a linguagem em movimento que produz efeitos de sentidos. Assim, o papel do analista é compreender a linguagem fazendo sentido enquanto elemento constitutivo dos sujeitos e de sua história. Para isso é necessário evidenciar as condições materiais de produção dos sentidos, isto é, o contexto em que os dizeres foram produzidos (Orlandi, 2013; Pêcheux, 2014). Em suma, é preciso compreender a exterioridade dos discursos (quem, quando, como se diz, o que já foi dito etc.) (Pires \& Sobral, 2013), o que não depende apenas das intenções dos interlocutores, haja vista que os efeitos de sentidos, de acordo com Pêcheux (2014), resultam de processos coletivos, simbólicos e históricos.

Para que seja possível constituir os sentidos nos discursos, é necessário que estes encontrem respaldo em uma memória discursiva (Interdiscurso): "o saber discursivo que torna possível todo o dizer e que retorna sob a forma de pré-construído, o já-dito que está na base do dizível" (Orlandi, 2013, p. 31). $\mathrm{O}$ interdiscurso funciona à revelia dos sujeitos e diz respeito a um conjunto de formulações que determinam o que é dito e que localiza esse dizer em uma formação discursiva (FD) específica. Esse processo é 
o que possibilita o discurso imediato (intradiscurso) (Orlandi, 2013; Pêcheux, 2014).

As FD são definidas como regionalizações/ regularidades do interdiscurso, que permitem compreender o processo de produção dos sentidos: ela é aquilo que, numa formação ideológica dada, levando-se em consideração a conjuntura sócio-histórica, determina o que pode e deve ser dito. Esse pressuposto de que há um já-dito que atua e sustenta os dizeres e sentidos é fundamental para compreender o funcionamento do discurso bem como a relação dos sujeitos com a Ideologia (Orlandi, 2013; Pêcheux, 2014). Para a AD, a linguagem é o lugar de manifestação da Ideologia (apagamento histórico das relações constitutivas dos sujeitos, naturalizando os processos de produção dos sentidos), bem como das ideologias (conjunto de representações em disputa pelos agrupamentos sociais). Deste modo, os interlocutores acreditam, equivocadamente, ser o ponto de partida dos sentidos, quando, na realidade, não o são (Orlandi, 2013; Pêcheux, 2014). Esse processo ocorre devido a dois funcionamentos inconscientes concernentes à linguagem: o Esquecimento Número 1 (esquecimento ideológico que reproduz em nossos discursos o modo pelo qual somos afetados pela Ideologia, ou seja, nosso desconhecimento acerca das condições materiais de produção dos discursos) e o Esquecimento Número 2 (suposição que o que dizemos só poderia ser da exata maneira como o foi e não outras, ou seja, ilusão de domínio do discurso) (Orlandi, 2013; Pêcheux, 2014).

As condições de produção dos discursos também são influenciadas por determinados mecanismos denominados de Formações Imaginárias: relações de sentido (não há discurso que não tenha relação com outros que o sustentam); antecipação imaginária (os sujeitos regulam sua argumentação de acordo com os efeitos que desejam produzir); e relações de força (legitimação social dos discursos) (Orlandi, 2013; Pêcheux, 2014).

A partir deste arcabouço conceitual, o dispositivo teórico, o analista busca compreender a forma como a linguagem afeta as produções de sentidos entre os interlocutores (Pêcheux, 2014). Assim, o corpus ou material linguístico dessa pesquisa foi composto pelo conjunto das entrevistas realizadas, o arquivo de referência discursiva (Guilhaumou, Maldidier, \& Robin, 2016). Todavia, para a AD, o posicionamento do analista e seus gestos de interpretação são inerentes à construção do dispositivo analítico (Orlandi, 2013). Portanto, nessa pesquisa, a escolha das enfermarias de ginecologia e obstetrícia partiu da suposição dos analistas de que esses cenários discursivos evidenciariam efeitos de sentidos (e práticas em saúde) considerados típicos para a feminilidade.

Quanto aos procedimentos de análise, considerou-se o seguinte percurso (Gomes, 2007; Orlandi, 2013): a) delimitação das sequências discursivas (trecho das entrevistas) que permitem, por sua regularidade de sentidos, identificar as principais FD do corpus, por meio das incidências do Interdiscurso e do Esquecimento 2; b) processo discursivo, relacionando as FD com as Formações Ideológicas, Formações Imaginárias e Esquecimento 1 na constituição dos sentidos.

Em relação aos aspectos éticos, esta pesquisa está amparada nas Resoluções no 466/2012 e no 510/2016 do Conselho Nacional de Saúde e foi submetida e aprovada pelo comitê de ética em pesquisa da universidade dos pesquisadores (CAAE: 62334116.6.0000.5154 na Plataforma Brasil) e pela Gerência de Ensino e Pesquisa do HC-UFTM.

\section{Resultados e discussão}

Os resultados serão apresentados em duas seções. A primeira discorre sobre os objetos discursivos e apresenta as principais FD de referência para este estudo, sendo estas: O corpo que reproduz e Ilusão de igualdade e a superioridade do discurso biomédico. Já a segunda versa sobre o processo discursivo.

\section{FD1: $O$ corpo que reproduz}

Quando questionadas a respeito dos principais motivos pelos quais procuravam os serviços de saúde e quais eram os profissionais que costumam procurar em seu dia a dia, as participantes destacaram o profissional da ginecologia como referência: "Vou ao médico sim, mas é raro. Não faço exame de rotina direto, não, mais o ginecologista mesmo, que é o comum da gente ir né" (Ana Carolina, 27 anos); "Mais que eu procuro é o ginecologista mesmo, né, mais normal, rotina, fazer Papanicolau, exame de lâmina e essas coisas" (Sofia, 18 anos); "Mais, assim, é a ginecologia, pra saber se não tem nada. Só esse que eu vou, na verdade, porque a gente, mulher, tem que ir" (Alice, 33 anos); e:

Eu vou, geralmente, bastante nos médicos, faço rotina de exames, procuro sempre ir no ginecologista e fazer a rotina da mulher. O que eu mais 
procuro é o ginecologista mesmo, fazer rotina né, eu gosto de estar fazendo o Papanicolau, o exame de mama e essas coisas, né (Jéssica, 32 anos).

A naturalização pela busca apenas do profissional de ginecologia como a principal especialidade da saúde para as mulheres destaca uma das principais características dessa FD. Por intermédio de expressões e justificativas como "que é o comum da gente ir" e "o mais normal", percebe-se o papel que o corpo feminino tende a ocupar no sistema de saúde e de que forma delimita as intervenções que supostamente deve receber.

Considerando que a forma como os sujeitos se filiam aos serviços de saúde e que as práticas de cuidado exercidas por estes são importantes para a compreensão dos processos de construção de suas identidades (femininas e/ou masculinas) (Marques, 2010; Schraiber, 2012; Villela et al., 2009;), ao direcionarem o autocuidado para a área de saúde reprodutiva, pode-se supor que a organização das próprias demandas em saúde (qual médico procurar e quando procurar etc.) reproduz sentidos acerca do que essas interlocutoras entendem "ser mulher" - sentidos sedimentados em uma memória discursiva (interdiscurso) que interpela (por meio dos Esquecimentos) os sujeitos (Pêcheux, 2014).

Pode-se destacar o relato de Jéssica que, em um primeiro momento, utilizou "rotina de exames" e, logo em seguida, o modificou para "rotina da mulher", cujo deslizamento de sentido (metáfora) ilustra a incidência do Esquecimento 2, haja vista que ela poderia ter mantido a primeira expressão sem limitar seus cuidados em saúde àqueles voltados à saúde reprodutiva. Assim, a representação simbólica do corpo feminino dotado da capacidade de reproduzir descendentes reitera sentidos cristalizados social e culturalmente, representados na assistência à saúde da mulher e definindo modalidades de cuidado que priorizam a saúde reprodutiva. Outra sequência discursiva que ilustra o Esquecimento 2 é de Alice, que justificou a procura pelo ginecologista "porque a gente mulher tem que ir", enfatizando a suposta obrigatoriedade das mulheres de cuidarem de seus corpos e suas funções reprodutivas, limitando os espaços nos quais elas transitam naquela instituição.

É interessante destacar outras sequências discursivas de algumas participantes (visto que nem todas estavam internadas pelo mesmo motivo) que reproduzem em seus discursos a legitimação do cuidado a partir do momento em que se encontram no ciclo gravídico puerperal: "Eu acho que agora as coisas vão mudar, daqui para frente eu acho que vou me cuidar mais. Ah, por causa mais do bebê, porque vou amamentar, daí tenho que estar bem para ele ficar bem" (Iris, 24 anos); e:

Antes, a minha médica falava que era para eu cuidar da diabete, para eu cuidar e comer menos, aí eu não comia menos, não [risos]. Eu comia, não cuidava da diabete, não queria saber desses trem. Mas agora, sabendo que eu tenho outra pessoa para cuidar dentro de mim, aí eu estou cuidando. Por causa da gestação que eu estou cuidando mais (Ângela, 18 anos).

Quando os meninos ficam doentes, eu já corro com eles pro médico, né. Lá em casa é pediatra que mais procuro, mas, pra mim, já faz muito tempo que eu não procuro. Lá, a gente tem que fazer mais por eles do que pela gente, né (Elena, 29 anos).

Um dos pontos importantes para entender o funcionamento do discurso e o modo como são estabelecidas as relações de produção de sentidos é atentar para o fato de que os sentidos das palavras mudam de acordo com a posição (marcadores das desigualdades sociais) daqueles que as empregam. Isso quer dizer que elas adquirem sentidos em referência às formações ideológicas nas quais estão inscritas, o que é denominado de posição discursiva (Orlandi, 2013; Pêcheux, 2014).

Nos casos anteriores, é possível perceber que, a partir do momento em que essas mulheres ocupam a posição discursiva "mãe", a preocupação com o cuidado é colocada em cena. $\mathrm{O}$ fato de relatar que só estão ali por causa da gravidez, de apontarem as diferenças que estão por vir em suas rotinas de cuidado e colocarem as demandas de saúde dos filhos em primeiro plano permite entender que essa posição recupera sentidos correspondentes a outros que os sustentam (interdiscurso) - nesse caso, relativos à mulher tradicionalmente responsável pelos cuidados dos descendentes e demais membros da família.

A utilização das expressões "agora, sabendo que eu tenho outra pessoa para cuidar dentro de mim", "tenho que estar bem para ele ficar bem" e "lá, a gente tem que fazer mais por eles do que pela gente" evidencia 
o modo como elas condicionam seus cuidados ao momento da gravidez, como se, em decorrência de serem ou estarem se tornando mães, devessem passar a cuidar mais de sua saúde, mesmo que não o fizessem antes. Destaca-se, aqui, o deslizamento de sentido enquanto constituintes dos discursos (passando da posição discursiva de "mulher" para "mãe"), o que gera diferentes significações do que é considerado apropriado para esses sujeitos. Ressalta-se também o uso das palavras "tenho" e "tem", denunciando a obrigatoriedade e urgência para que estejam bem e saudáveis para cuidar de seus filhos. Essas sequências discursivas reafirmam (interdiscursivamente) a valorização social da maternidade para as mulheres.

É possível observar também, em outras sequências discursivas das entrevistas, a generificação do discurso no campo da saúde, associando as práticas de cuidado ao feminino/mulheres e a distanciando do masculino/homens, estabelecendo modos distintos de autocuidados e de relações com o sistema de saúde. Quando questionadas a respeito das principais diferenças entre mulheres e homens nos cuidados em saúde, as participantes relataram as diferenças de gênero enquanto balizadoras dos cuidados:

Mulher cuida bem mais, já homem não cuida muito. Depende né, tem homem que cuida, mas na maioria não cuida. Não sei por que isso acontece, mas mulher acho que tem mais problemas de saúde, até por causa desse negócio ginecológico, de ter filhos e essas coisas, acarreta em mais problemas. Homem não, homem não tem menstruação, homem não tem cólica, homem não tem nada (Marcela, 34 anos).

Eu penso comigo que mulher, a possibilidade de ela ter mais problema é maior. Acho que ela é mais frágil. Eu sempre acompanho meu filho e, quando meu esposo precisa e ele está muito ruim, aí eu vou com ele (Jéssica, 32 anos).

Ah, eu não sei te falar as diferenças, mas eu falo que é diferente. Mulher com certeza cuida mais né? Ou não [risos]. Acho que mulher é mais cuidadosa. Às vezes, o homem também, alguns homens também. É que homem, às vezes, depende mais da mulher, né. Mas mulher pode cuidar sozinha, o homem não. Mas, às vezes, pode ser a mesma coisa, né, ou é imaginação minha (Ângela, 18 anos).
É bem equilibrado, acho que não tem aquilo de o homem cuida mais, a mulher cuida mais. Meu marido, por exemplo, cuida mais, acho que ele é mais manhoso, na verdade, acho que ele é mais mole. Acho que eu sou mais forte do que ele, porque qualquer coisinha ele já está no médico (Elena, 29 anos).

A suposição de que as mulheres cuidam ou deveriam cuidar mais da própria saúde devido a sua natureza biológica e reprodutiva é o que norteia seus discursos, como representado nos trechos anteriores. $E$ interessante considerar que os adjetivos "frágil", "cuidadosa" e "preocupada" (utilizadas pelas participantes), bem como as características empregadas por Elena para designar seu marido (manhoso e mole) se associam a um espaço discursivo de cuidados marcadamente delegado às mulheres e denunciam as incidências do Esquecimento 2 (enunciação) (Orlandi, 2013; Pêcheux, 2014).

Assim, a suposição de que mulheres seriam mais predispostas ao adoecimento e que deveriam exercer a função de cuidadora dos demais membros da família devido ao simples fato de serem mulheres, para além de estabelecer posições assimétricas entre os gêneros, se configura como uma forma regulatória dos modos de oferta de cuidado e de adoecimento distintos a partir do processo de reiteração (Butler, 2015), assumindo o efeito de normalidade. No entanto, partindo do pressuposto de que não há discurso que não se relacione com outros, sendo os efeitos de sentidos resultantes dessas relações (Orlandi, 2013; Pêcheux, 2014), esse não é um sentido produzido especificamente no contexto hospitalar e no campo da saúde e serve de munição a um processo que visa disciplinar masculinidades e feminilidades - e ao processo ideológico que supõe os homens superiores às mulheres.

Assim, são os tradicionalismos e estereótipos de gêneros construídos social e historicamente que cristalizam os modos de relações entre e intragêneros disponíveis no interdiscurso e que orientam as formulações dessas participantes. Ao serem afetados pela memória discursiva, determinados sentidos são permitidos e outros negados (Orlandi, 2013; Pêcheux, 2014) - aproximação do feminino aos cuidados em saúde e afastamento do masculino aos cuidados de saúde. Nessa perspectiva, os sentidos disponíveis a respeito do feminino pressupõem atividades para as quais as mulheres estariam mais aptas, como autocuidado, maternidade, entre outros (Butler, 2015). 


\section{FD 2: Ilusão de igualdade e a superioridade do discurso biomédico}

Segundo Pêcheux (2014), as FD não são blocos homogêneos de produção e de regulação dos sentidos, mas são compostas por elementos processos heterogêneos e por vezes contraditórios, possibilitando configurações e reconfigurações contínuas em suas relações com os sujeitos e com o interdiscurso. Assim, buscou-se, para além do desvelamento das ilusões ocasionadas pelo funcionamento dos esquecimentos e do interdiscurso, discutir de quais formas essas contradições se constituem enquanto estruturantes do funcionamento da linguagem naquele contexto específico.

Dentre as diferentes possibilidades de produção de sentidos que essa segunda FD permite, destacam-se as respostas à pergunta "Quando, em atendimento com profissionais da saúde, você tem preferência por profissionais homens ou mulheres?”. Dez das treze participantes responderam ter preferência pela profissional da saúde do gênero feminino em relação à especialidade de ginecologia: " $E u$, se fosse para preferir, eu acharia melhor mulher. A gente se sente mais... como a gente é mulher, a gente fica com mais liberdade, né, de se abrir, eu acho mais fácil' (Edna, 48 anos); e:

Não, tanto faz. Eu me sinto mais à vontade com mulher, né. Acho que você me entende, né? Mas prefiro nenhum dos dois não. Porque assim, vai tirar roupa, fazer exame de toque, com homem a gente fica um pouco constrangida (Clarice, 31 anos).

Ah, mulher né. Porque depende do exame que for fazer também, porque, para mim, também, qualquer um serve. Tipo, ginecologista, prefiro mulher, porque dá vergonha. No meu pensamento, a mulher, para fazer consulta de falar e esses trem, aí a mulher é melhor de falar (Ângela, 18 anos).

Mulheres, porque me sinto mais à vontade quando é mulher. Principalmente se eu não conheço, eu vou para o lado da mulher. Igual, meu pré-natal todo foi com um homem, mas porque me encaminharam para ele. Mas eu fui de boa, fiz com ele o pré-natal inteiro. Mas, se for para escolher sem eu conhecer, eu vou me sentir melhor com mulher. Mas é porque eu sou cismada, acho que é coisa minha (Elena, 29 anos).
Nessas sequências discursivas, é importante destacar que, por mais que algumas participantes em um primeiro momento relataram que tanto faz o gênero do profissional que realiza o atendimento, na sequência (deslizamentos de sentido), destacaram que a preferência existe. Assim como na FD anterior, novamente as participantes destacaram em suas respostas profissionais referentes à especialidade de ginecologia, embora a pergunta não apresentasse nenhum elemento que direcionasse o questionamento apenas para essa área da saúde.

Esse apontamento permite evidenciar as incidências do Esquecimento 2 (Orlandi, 2013; Pêcheux, 2014), pois elas poderiam ter mencionado quaisquer áreas da saúde (tanto das especialidades médicas como diferentes categorias: enfermagem, psicologia, nutrição, fisioterapia, entre outros), no entanto não o fizeram. A memória discursiva interpela as participantes e, por isso, elas destacaram a especialidade de ginecologia, estabelecendo efeitos de sentidos que localizam as mulheres nos espaços de saúde e cuidados. Esse movimento pode ser interpretado como uma impossibilidade de se formular sentidos diferentes daqueles constituídos e sedimentados no interdiscurso que partem de uma perspectiva biomédica do atendimento em saúde, enfatizando fatores biológicos como lócus do cuidado, bem como os médicos como principais cuidadores.

Outro mecanismo a ser destacado nessa FD é o de antecipação imaginária pela qual pode ser observada a regulação da argumentação das participantes. Nas sequências discursivas de Clarice (" $E u$ me sinto mais à vontade com mulher né, mas prefiro nenhum dos dois, não") e de Ângela (“Ah, mulher, né. Porque depende do exame que for fazer, também, porque, para mim, também, qualquer um serve") isso fica evidente a partir do jogo de retificação: disseram que tinham preferência e, depois, corrigiram afirmando indiferença quanto ao gênero dos profissionais de saúde. Isso ocorreu também com Elena, que disse se sentir melhor quando atendida por mulheres, mas, no decorrer de sua argumentação, relatou sobre o pré-natal acompanhado por um profissional do gênero masculino (Orlandi, 2013; Pêcheux, 2014). Tal processo pode ter ocorrido pelo motivo de saberem, a priori, que participavam de uma pesquisa sobre o tema gênero, bem como pelo fato de a entrevistadora se apresentar como profissional da saúde vinculada à instituição na qual elas estavam internadas. Dessa forma, pode ter havido tentativa de regular 
sua argumentação de acordo com o efeito que desejavam produzir na sua interlocutora/entrevistadora.

Como complemento da pergunta anterior, foi questionado se essas mulheres já haviam expressado suas opiniões e preferências sobre o gênero do profissional que realiza as consultas e intervenções em saúde e se alguém no hospital já havia realizado essa pergunta. Todas as participantes afirmaram nunca terem discutido ou terem sido consultadas sobre essas preferências com profissionais da saúde, sendo a entrevistadora a primeira a fazer isso.

Considerando as condições de produções de sentidos que participam dessa pesquisa - a exterioridade que também compõem a significação (Orlandi, 2013; Pêcheux, 2014) -, cabe discorrer a respeito do fato de as entrevistas terem ocorrido dentro de uma instituição hospitalar atravessada por relações de poder (entre diferentes profissões e entre profissionais e pacientes), bem como o fato de a entrevista ter sido feita por uma profissional de saúde vestida com um jaleco branco (norma da instituição), similarmente aos outros profissionais daquela instituição. Por mais que seja possível perceber que em determinados momentos as participantes se identificaram com a entrevistadora mulher (como nos exemplos: "porque a gente, mulher, tem que ir"; "eu me sinto mais à vontade com mulher né, acho que você me entende, né?"), é pertinente questionar os motivos pelos quais essa pergunta não se viabiliza naquele contexto por parte dos profissionais e o porquê daquelas mulheres não expressarem sua opinião sobre esse assunto.

Outra sequência discursiva que permite tal questionamento é a de Clarice (em complemento a resposta de que nunca havia mencionado esse tipo de preferência):

Como a gente trata pelo Sistema Único de Saúde, eu reparo que assim "ah, você já está de graça aqui, você já está pelo SUS e ainda quer escolher se é homem ou mulher? Quem vai te olhar e quem não vai?". Acho que tinha que ter um pouco de respeito. É claro que a gente tem que aceitar quem quer nos ajudar, mas acho que, também, a opinião tem que contar. É igual você chegar em uma loja de roupa e você quer ser atendida por uma mulher. Por quê? Porque talvez a opinião dela te ajude a comprar, te ajude a dar certo. Aí você pode escolher se você quer a vendedora ou o vendedor, não pode? Mas é porque você tá pagando, entendeu? Agora, no hospital, a gente não pode ter essa escolha. Então a gente tem que ter o bom senso de aceitar quem vem ajudar, né. Porque você não pode ficar escolhendo muito, entendeu? Eu penso assim (Clarice, 31 anos).

Nesse recorte, é possível notar que ela considera a saúde sob a perspectiva do favor e da caridade. Torna-se interessante destacar o termo "bom senso", utilizado pela participante, que remete ao não reagir às imposições realizadas pelo sistema de saúde por mais violentas que elas possam ser, o que faz que ela não questione a qualidade de um atendimento.

Ademais, observou-se uma contradição no discurso da participante que colocou em oposição a ideia de que as usuárias deveriam poder escolher ao mesmo tempo em que precisam ter o bom senso de não questionar e aceitar o que lhes é oferecido. Suas preferências e argumentações deveriam ser consideradas, mas, uma vez que adentram o serviço de saúde público e gratuito e assumem a posição discursiva de paciente, esse direito lhes é negado pela justificativa do bom senso. Esse funcionamento demarca como se constituem os espaços de produção discursiva e a exterioridade da e na formação dos sentidos. Ainda sobre esse recorte, é possível observar o modo como os esquecimentos constituem os sujeitos e os sentidos - tanto a ilusão referencial de domínio da fala (Esquecimento 2) quanto a ilusão de transparência entre pensamento (consciência) e a intencionalidade do dizer.

Outro eixo norteador dessa FD foi a suposição de igualdade nos atendimentos em saúde. Quando questionadas se consideravam importante homens e mulheres receberem cuidados diferenciados pelos profissionais durante a internação, as respostas transitaram em torno da crença de que a diferenciação deve observar apenas questões diagnósticas, e não de gênero: "Não, depende dos cuidados, cada um precisa de um cuidado. Mas assim, por mim, não precisa ser diferente, homem e mulher é a mesma coisa, só muda o sexo" (Ângela, 18); e:

Depende do que eles têm, né, da doença que a pessoa tem, né. Talvez, ela tem alguma coisa e eu tenho outra, aí, talvez eu precise de mais atenção, de mais médicos e profissionais ao meu redor, mas não porque ele é homem, porque ele tem câncer, né. Claro que os corpos são diferentes, o psicológico da mulher deve ser mais diferente do que o homem, né. Mas eu acho que tem que ser 
pela doença, não pelo sexo da pessoa. E também não concordo em ser tratado melhor ou pior porque é homem ou mulher, isso não existe. Existe, sim, né? Existe demais (Clarice, 31).

Não, acho que não, tem que ser igual, né. A gente, às vezes, não tem muita autoridade no lugar de saúde, como estou te falando... agora, se for um homem, muitas vezes, qualquer coisa que ele falar, eles fazem mais a vontade dele, igual a gente, como é mulher, não faz nada, aí vai deixando; agora o homem [...] respeitam mais (Marcela, 34).

A igualdade se restringe, assim, ao momento da internação, mas a intervenção em saúde deve responder as especificidades que cada corpo/doença necessita. Quando Ângela afirmou "por mim, não precisa ser diferente, não, homem e mulher é a mesma coisa, né, só muda o sexo", foi possível notar que os efeitos de sentidos produzidos apontavam para uma mudança que só afetaria o corpo biológico dos sujeitos, relegando a um segundo plano os determinantes sociais e culturais que circunscrevem tal diferença.

As dificuldades dessas participantes de romperem com o processo parafrástico de produção de sentidos sobre o contexto de saúde podem ser compreendidas como efeito da cristalização dos sentidos. Assim, reitera-se, por meio das sequências discursivas dessas participantes, que os serviços de saúde são atravessados por um modelo clínico e tradicional de assistência sanitária de massa que, além de dificultar a individualização das necessidades psicossociais (Bedrikow \& Campos, 2011), modaliza a disponibilização de sentidos (as intervenções devem abarcar prioritariamente as demandas fisiológicas e anatômicas).

Em contrapartida, por mais que essas sequências discursivas estejam afetadas pelas determinações disponíveis na memória discursiva, destacar-se a fala de Clarice que, em um primeiro momento, afirmou que o tratamento deve ser igual para homens e mulheres, mas, em seguida, propôs que existem outras diferenças a serem consideradas ("claro que os corpos são diferentes, o psicológico da mulher deve ser mais diferente do que o homem, né"). Sua resposta enfatizou, ainda, que não concorda que um gênero deva ser tratado melhor que o outro: "Isso não existe" e, após uma longa pausa, disse "Existe sim, né? Existe demais".

Ao mesmo tempo em que ela reproduziu em sua fala que a igualdade deve ser o ponto de partida para a diferenciação no atendimento, ela reconheceu que não é isso o que acontece. Considerando a FD em questão, o caráter coletivo e histórico da linguagem, e o fato de que não há discurso que não se relacione com outros relações de sentidos (Orlandi, 2013; Pêcheux, 2014) -, um dos efeitos de sentidos desse recorte é que a participante não se referiu apenas ao contexto de saúde como palco para desigualdades entre os gêneros. Como os gêneros são práticas veiculadas por sujeitos sócio-históricos imersos em contextos políticos (relações de poder) específicos, as desigualdades se materializam em diferentes cenários, dentre ao quais estão os serviços de saúde. Em consonância a isso, é possível destacar a resposta de Marcela que, com o termo "autoridade", referiu como os homens transitam dentro daquela instituição, reafirmando que os homens são mais respeitados do que as mulheres.

\section{Processo discursivo}

Após a identificação das FD, é preciso discorrer sobre o processo discursivo, ou seja, como as Formações Imaginárias (FImag), as Formações Ideológicas (FI) e o Esquecimento Número 1 incidem na constituição dos sentidos produzidos pelos/entre sujeitos. Para tanto, é necessária a articulação do que foi discutido com as políticas públicas de saúde, o conjunto de programas, ações e decisões que visam assegurar direitos para os grupos respeitando suas especificidades (Böing \& Crepaldi, 2010), enquanto constituintes dos discursos (Orlandi, 2013; Pêcheux, 2014) das participantes, pois são evocados sentidos acerca do que é considerado adequado para esse segmento (mulheres) no sistema de saúde.

As sequências discursivas utilizadas para constituição do corpus dessa pesquisa permitem considerar que os discursos das participantes, no que se refere à forma como se filiam aos serviços de saúde, se organizam prioritariamente em torno da discursividade sobre maternidade. É relevante esclarecer que, por mais que a pesquisa tenha sido realizada nas enfermarias de ginecologia e obstetrícia, parte significativa da amostra $(\mathrm{n}=6)$ não estava internada por motivos relacionados à gravidez. Nesse sentido, destaca-se também que tal perspectiva ainda se configura como norteadora para as campanhas de saúde da mulher que, por meio de suas práticas e políticas públicas, priorizam a assistência voltada ao ciclo gravídico puerperal (Costa-Júnior, Couto, \& Maia, 2016) e podem negligenciar outros temas relacionados à 
saúde das mulheres, como violência doméstica, saúde mental, sofrimento advindo da jornada dupla/tripla de trabalho, exercício da sexualidade desvinculada do objetivo da reprodução, entre outros (Botton, Cúnico, \& Strey, 2017; Cadona \& Strey, 2014).

Schwengber e Meyer (2015) discutem a respeito da imposição sobre os corpos femininos para que eles sejam alvos constantes de aperfeiçoamentos e correções estéticas e da necessidade de desenvolverem habilidades para, além de gerar, cuidar de outras vidas. As participantes reproduziram nas entrevistas a naturalização da forma como as mulheres devem se relacionar com o próprio corpo e com o sistema de saúde por meio da suposta predisposição feminina à fragilidade, vulnerabilidade diante do adoecimento e necessidade de cuidados, justificados como prevenção à reprodução e, assim, garantem o que é tradicionalmente delegado à mulher: maternidade e reprodução biológica.

Quanto ao processo de naturalização baseada no gênero, Butler (2015) o entende como originário de práticas discursivas que respondem a interesses sociais, políticos e econômicos, cujo objetivo é adequar os sujeitos às normas de condutas específicas para cada um dos gêneros, mantendo os privilégios de uns (homens) sobre outros (mulheres). Para essa autora, gênero se constitui como um instrumento que configura as relações de poder e permite que as determinações de feminino e masculino (por meio da repetição e reiteração) sejam naturalizadas. Assim, o sujeito e seu gênero seriam resultados não de profundidades biológicas, mas, sim, de atos performáticos que objetivam estabilizar a identificação com determinado sexo, numa ilusão de estabilidade entre biologia, gênero e orientação sexual que sustenta parte significativa das desigualdades sociais.

Sob a perspectiva da $\mathrm{AD}$, essa naturalização dos processos de produção de sentidos ocorre por vias da Ideologia (apagamento das relações de poder entre os sujeitos e a ilusão de transparência da linguagem), fazendo que os sujeitos só tenham acesso a parte do que dizem. Em outras palavras, é necessário que o indivíduo seja interpelado em sujeito pela Ideologia para que o dizer seja produzido (Orlandi, 2013; Pêcheux, 2014). Assim, a Ideologia interpela os indivíduos em sujeitos generificados - ou homens, ou mulheres.

É a partir desse argumento que Pêcheux (2014) destaca os esquecimentos como estruturantes dos sujeitos, tendo em vista que é por meio deles que há apropriação de discursos produzidos no coletivo
(Esquecimento 1), fato este demarcado nas sequências discursivas das participantes por meio da utilização de expressões individualizantes como "eu penso assim" (Clarice), "acho que isso é coisa minha" (Elena) e "no meu pensamento" (Ângela). Então, ao mesmo tempo em que essas mulheres reiteram discursos produzidos social, cultural e historicamente, elas buscam resguardar seu lugar de autoria (Orlandi, 2013; Pêcheux, 2014).

Outro elemento importante nesse processo discursivo é considerar a sociedade como organização de relações hierarquizadas (relações de força) - o lugar a partir do qual fala o sujeito é constitutivo do que por ele é dito. Para Pêcheux e Fuchs (1997), os discursos são afetados pelos efeitos de dominância e os sentidos que se sobrepõem aos demais o fazem por causa de relações de poder de uma sociedade. Isso é relevante no cenário desta pesquisa (hospital): no decorrer das entrevistas, foi possível considerar que determinados discursos foram priorizados e valorizados - no caso, os tradicionalismos de gênero que delegam ao feminino características e normas de conduta ligadas à maternidade e ao cuidado de si e dos outros -, a valorização do especialista, representado pelos profissionais de medicina, e as abordagens biomédicas, centradas nas demandas biológicas. Essas priorizações vêm acompanhadas de silenciamento de outras demandas concernentes à saúde da mulher, bem como enfatizam esses serviços como espaços de favores, e não de direitos.

De acordo com a AD, esse silenciamento ou política do silêncio também constitui os sentidos que podem circular naquele espaço. Pêcheux (2014) distingue o silêncio constitutivo (processo em que uma palavra toma o lugar e/ou apaga a outra) do silêncio local (censura, ou seja, aquilo que é proibido de ser dito em certa conjuntura). Tal funcionamento se dá pelo fato de as relações de poder em uma sociedade produzirem espaços e momentos de censura. Assim, em uma instituição hospitalar, determinados dizeres são possibilitados e outros são vetados. Em relação às posições discursivas que lá estão em jogo, as figuras de autoridade se concentram nos profissionais de saúde, logo supõe-se o efeito de dominância de/em seus discursos (Orlandi, 2013; Pêcheux, 2014). Isso é ilustrado por meio de alguns apontamentos das participantes que, por mais que ocupem posições diferentes, reproduzem o modo como são afetadas pela Ideologia, reiterando em seus discursos que devem se submeter às intervenções em saúde sem questionamentos e/ou exigências. 
Ainda em relação aos contextos hospitalares, não raro os sujeitos são reduzidos a um diagnóstico ou ao número do leito. Dessa forma, os usuários são privados de seus nomes, pertences e das suas singularidades, dentre elas, as de gênero (Silva, 2009; Straub, 2014). Assim, os determinantes sociais de gênero na saúde podem ser obliterados, sofrendo os efeitos da censura (Pêcheux, 2014). Porém a visibilidade desse gender blindness (silenciamento/cegueira das questões de gênero) vem ganhando destaque nos estudos sobre práticas assistenciais em saúde (Marques, 2010), apesar de tanto gestores quanto profissionais da saúde apresentarem dificuldades dessa temática em suas práticas (Aquino, 2006; Villela et al., 2009). Esse processo de silenciamento, de acordo com Schraiber (2012), age em consonância com e a favor dos modelos clínicos tradicionais de assistência biomédica, tecnicista e curativista em saúde.

Destaca-se, portanto, a matriz hegemônica do modelo biomédico na organização dos serviços de saúde, obstaculizando a implementação e o pleno funcionamento dos modelos de integralidade. Em decorrência disso, pôde-se perceber, nas sequências discursivas que compuseram o corpus dessa pesquisa, a reiteração desse modelo de funcionamento por meio da repetição parafrástica de um não reconhecimento das dimensões sociais e culturais que perpassam a diferenciação entre os gêneros (Orlandi, 2013; Pêcheux, 2014). Assim, os estereótipos e desigualdades de gênero advindos de uma sociedade patriarcal ficam despercebidos, apesar de seus efeitos e consequências serem reais, sob a justificativa da igualdade no atendimento (biomédico) em saúde.

De acordo com Araújo (2015) e Rodrigues (2015), essa falta ou pouco reconhecimento por parte dos usuários ou dos profissionais dificulta a implementação das políticas públicas em saúde. Por exemplo, por mais que a PNAISM seja vista como resultado dos movimentos feministas (que muito colaboraram para a desconstrução de uma perspectiva reducionista de atendimento em saúde para as mulheres, introduzindo, na agenda política, temas pouco considerados), a maioria das ações e estratégias propostas se mantêm relacionadas à saúde sexual e reprodutiva das mulheres, cujos exemplos são as campanhas de prevenção do câncer de colo do útero, do câncer de mama e o programa Rede Cegonha. Essas campanhas são de suma importância para a saúde das mulheres, no entanto não contemplam a integralidade da saúde.
Considerando o cenário, as participantes e o contexto específico desta pesquisa, é importante destacar algumas das ações em prol da saúde das mulheres no estado de Minas Gerais. Uma delas é desenvolvida pela Secretaria de Estado de Saúde de Minas Gerias e é intitulada "Seu corpo suas regras, a primeira delas é a prevenção" (Brasil, 2019) que, apesar de apresentar uma perspectiva de integralidade em saúde que contemple as condições diferenciadas resultantes dos determinantes sociais de saúde que causam impactos nos diversos grupos de mulheres, seu material de divulgação e suas ações enfatizam a prevenção, o autocuidado, o enfretamento e o tratamento dos cânceres de mama e do colo do útero (enfatizados na campanha Outubro Rosa). Outra ação é desenvolvida em conjunto pelas Secretarias de Estado de Direitos Humanos, de Estado de Participação Social e Cidadania e Subsecretaria de Políticas para Mulheres, o Plano Decenal de Políticas para Mulheres do Estado de Minas Gerais (Brasil, 2018), que apesar de abordar vários eixos - autonomia econômica das mulheres, enfrentamento à violência contra as mulheres, participação política das mulheres, e construção de relações igualitárias entre os gêneros - no que diz respeito à saúde integral das mulheres, enfatiza quase exclusivamente as demandas concernentes aos direitos sexuais e reprodutivos.

Obviamente, essas duas ações são importantes para mitigar algumas das desigualdades e agravos de saúde das mulheres, mas elas são insuficientes para abordar a saúde de maneira integral - a própria descrição dessas ações somada aos relatos das participantes indica que, no cenário investigado, há prioridade das demandas e cuidados que circundam as práticas e significados relacionados à saúde reprodutiva e os tradicionalismos de gênero (Costa-Júnior et al., 2016; Botton et al., 2017).

Em suma, esses elementos seriam indicativos de uma FI que situa as mulheres como sujeitos que devem exercer a maternidade - todavia não se trata, no escopo deste estudo, de averiguar se os serviços/ profissionais da saúde respondem adequadamente às orientações político-sanitárias (o que, aliás, seria adequado), mas de compreender que, naquele espaço/ cenário, foram e são produzidos discursos que correspondem aos sentidos cristalizados historicamente sobre o que é ser mulher (mãe e cuidadora). Por meio das relações de força e de sentidos presentes nas sequências discursivas apresentadas, ficam evidenciados os padrões atitudinais de gênero considerados adequados que devem ser performatizados por aquelas mulheres 
(Butler, 2015; Orlandi, 2013; Pêcheux, 2014) e dos quais desigualdades podem ser acentuadas.

\section{Considerações finais}

No esforço de compreender as formações discursivas de gênero relativas aos cuidados em saúde de mulheres internadas nas enfermarias de ginecologia/ obstetrícia em uma instituição hospitalar, considerou-se o campo da saúde (em especial o hospital) como espaço discursivo de (re)produção de estereótipos e desigualdades de gênero, alicerçado em Formações Ideológicas e Imaginárias que são constituintes dos modos como os sujeitos transitam naquele contexto.

Diante da necessidade de um reconhecimento das assimetrias de gênero bem como dos determinantes sociais enquanto componentes do processo saúde-doença, éimportante uma reorientação das políticas públicas e das práticas em saúde, visando organizar modelos de assistência integrais que contemplem aspectos subjetivos e sociais das usuárias, promovendo melhorias no atendimento. Assim, o campo da saúde precisa ser alvo de constante questionamento.
Por fim, enfatiza-se a necessidade de estudos que se debrucem sobre discursos de outros sujeitos que participam do sistema de saúde (usuários, profissionais e gestores). É igualmente importante apontar que uma perspectiva que abarque diversos determinantes sociais do processo saúde-doença (por exemplo, uma abordagem interseccional que contemple gênero, orientação sexual, raça/etnia e classe social) auxiliaria em sua compreensão de modo mais abrangente.

Ademais, as análises empreendidas buscaram sinalizar o quanto os estereótipos e tradicionalismos de gênero permeiam e são constituintes das práticas em saúde. A intenção dos analistas desta pesquisa não é a de propor segmentações para os diferentes setores e sujeitos baseados em seus gêneros - o que acentuaria a fragmentação da assistência em saúde. Propõe-se, portanto, a compreensão das questões de gênero como conteúdo transversal a todas as áreas e contextos de saúde, partindo da perspectiva de que uma melhor compreensão do gênero (enquanto um dos determinantes sociais de) na área da saúde pode favorecer a oferta de programas e serviços condizentes com as reais demandas e necessidades das populações.

\section{Referências}

Alves, T. M. (2018). Interfaces entre gênero e saúde mental abordadas por estudos qualitativos das ciências sociais e humanas: Foco nas experiências subjetivas. Gênero, 18(2), 155-177. https://doi.org/10.22409/rg.v18i2.1149

Aquino, E. M. L. (2006). Gênero e saúde: Perfil e tendências da produção científica no Brasil. Revista de Saúde Pública, 40(spe), 121-132. http://dx.doi.org/10.1590/S0034-89102006000400017

Araújo, M. F., Schraiber, L. B., \& Cohen, D. D. (2011). Penetração da perspectiva de gênero e análise crítica do desenvolvimento do conceito na produção científica da saúde coletiva. Interface - Comunicação, Saúde, Educação, 15(38), 805-818. http://dx.doi.org/10.1590/S1414-32832011005000039

Araújo, M. J. O. (2015). Modelos de atenção à saúde mental das mulheres: Linhas de cuidado na perspectiva dos direitos humanos, gênero e integralidade na saúde. In T. Negrão, R. Vargas, \& L. P. Rodrigues (Orgs.), Saúde mental e gênero: Novas abordagens para uma linha de cuidado (pp. 55-76). Coletivo Feminino Plural.

Bedrikow, R., \& Campos G. W. S. (2011). Clínica: A arte de equilibrar a doença e o sujeito. Revista Associação Médica Brasileira, 57(6), 610-613. http://dx.doi.org/10.1590/S0104-42302011000600003

Böing, E., \& Crepaldi, M. A. (2010). O psicólogo na atenção básica: Uma incursão pelas políticas públicas de saúde brasileiras. Psicologia: Ciência e Profissão, 30(3), 634-649. http://dx.doi.org/10.1590/S1414-98932010000300014

Botton, A., Cúnico, S. D., \&Strey M. N. (2017). Diferenças de gênero no acesso aos serviços de saúde:Problematizações necessárias. Mudanças: Psicologia da Saúde, 25(1), 67-72.https://doi.org/10.15603/2176-1019/mud.v25nlp67-72

Brasil. (2004). Ministério da Saúde. Secretaria de Atenção à Saúde. Departamento de Ações Programáticas Estratégicas. Política nacional de atenção integral à saúde da mulher: Princípios e diretrizes. Ministério da Saúde.

Brasil. (2018). Plano decenal de políticas para mulheres. Subsecretaria de Políticas para Mulheres.

Brasil. (2019). Seu corpo, suas regras: A primeira delas é a prevenção. Secretaria de Estado de Saúde de Minas Gerais. https://www.saude.mg.gov.br/saudedamulher

Butler, J. (2015). Problemas de gênero: Feminismo e subversão da identidade. Civilização Brasileira. 
Cadona, E., \& Strey, M. N. (2014). A produção da maternidade nos discursos de incentivo à amamentação. Revista Estudos Feministas, 22(2), 477-499. http://dx.doi.org/10.1590/S0104-026X2014000200005

Conselho Federal de Psicologia. (2019). Referências técnicas para atuação de psicólogas(os) na atenção básica à saúde. CFP. https://site.cfp.org.br/publicacao/referencias-tecnicas-para-atuacao-de-psicologasos-na-atencaobasica-a-saude/

Costa-Júnior, F. M., Couto, M. T., \& Maia, A. C. B. (2016). Gênero e cuidados em saúde: Concepções de profissionais que atuam no contexto ambulatorial e hospitalar. Sexualidad, Salud y Sociedad, 23, 97-117. http://dx.doi.org/ 10.1590/1984-6487.sess.2016.23.04.a

Couto, M. T., \& Dantas, S. M. V. (2016). Gênero, masculinidades e saúde em revista: A produção da área na revista Saúde e Sociedade. Saúde e Sociedade, 25(4), 857-868. http://dx.doi.org/10.1590/s0104-12902016172308

Gomes, A. M. T. (2007). Do discurso às formações ideológica e imaginária: Análise de discurso segundo Pêcheux e Orlandi. Revista de Enfermagem da UERJ, 15(4), 555-562.

Guilhaumou, J., Maldidier, D., \& Robin, R. (2016). Efeitos do arquivo. In J. Guilhaumou, D. Maldidier, \& R. Robin, Discurso e arquivo (pp. 115-140). Editora Unicamp.

Louro, G. L. (2003). Gênero, sexualidade e educação: Uma perspectiva pós-estruturalista. Vozes.

Machin, R., Couto, M. T., Silva, G. S. N., Schraiber, L. B., Gomes, R., Figueiredo, W. S., Valença, O. A. V., \& Pinheiro, T. F. (2011). Concepções de gênero, masculinidade ecuidados em saúde:Um estudo com profissionais de saúde da atenção primária. Ciência e Saúde Coletiva, 16(11), 4503-4512. http://dx.doi.org/10.1590/S1413-81232011001200023

Marques, A. M. (2010). Gênero e saúde: Uma relação ainda oculta. In M. N. Strey, C. Nogueira, \& M. R. Azambuja (Orgs.), Gênero \& saúde: Diálogos ibero-brasileiros (pp. 35-58). EDIPUCRS.

Martin, M., Montanari, P. M., Pereira, P. P. G., Hamburguer, F. G., \& Silveira, C. (2018). As contribuições das ciências sociais e humanas no campo da saúde coletiva:Vinte anos da revista Interface - Comunicação, Saúde, Educação. Interface - Comunicação, Saúde, Educação, 22(67), 1029-1042. http://dx.doi.org/10.1590/1807-57622017.0219

Motta, J. I. J. (2016). Sexualidades e políticas públicas: Uma abordagem queer para tempos de crise democrática. Saúde Debate, 40, 73-86. http://dx.doi.org/10.1590/0103-11042016s07

Orlandi, E. P. (2013) Análise do discurso: Princípios e procedimentos. Pontes.

Osmo, A., \& Schraiber, L. B. (2015). O campo da saúde coletiva no Brasil: Definições e debates em sua constituição. Saúde e Sociedade, 24(suppl. 1), 205-218. http://dx.doi.org/10.1590/s0104-12902015s01018

Pêcheux, M. (2014). Semântica e discurso: Uma crítica à afirmação do óbvio. Unicamp.

Pêcheux, M., \& Fuchs, C. (1997). A propósito da análise automática do discurso: Atualização e perspectivas. In F. Gadet \& T. Hak (Orgs.), Por uma análise automática do discurso (pp. 163-252). Unicamp.

Pires, V. L., \& Sobral, A. U. (2013). Implicações do estatuto ontológico do sujeito na teoria discursiva do Círculo Bakhtin, Medvedev, Voloshínov. Bakhtiniana: Revista de Estudos do Discurso, 8(1), 205-219. http://doi.org/ $10.1590 /$ S2176-45732013000100013

Rodrigues, T. F. (2015). Desigualdade de gênero e saúde: Avalição de políticas de atenção à saúde da mulher. Revista Cantareira, 22, 203-216.

Schraiber, L. B. (2012). Necessidades de saúde, políticas públicas e gênero: A perspectiva das práticas profissionais. Ciência \& Saúde Coletiva, 17(10), 2.635-2.644. https://doi.org/10.1590/S1413-81232012001000013

Schwengber, M. S., \& Meyer, D. E. Gravidez. (2015). In A. M. Colling, \& L. A. Tedeschi (Orgs.), Dicionário crítico de gênero (pp. 316-319). UFGD.

Sen, G., George, A., \& Östlin, P. (2002). Engendering health equity: A review of research and policy. In G. Sen, A. George, \& P. Östlin (Orgs.), Engendering international health: The challenge of equity (pp. 1-34). MIT Press.

Silva, J. M. N., Paulino, D. B., \& Raimondi, G. A. (2020). Gênero e sexualidade na graduação em saúde coletiva do Brasil. Ciência \& Saúde Coletiva, 25(6), 2335-2346. https://dx.doi.org/10.1590/1413-81232020256.25822018

Silva, L. C. (2009). O cuidado na vivência do doente de câncer: Uma compreensão fenomenológica. UEM.

Souto, K. M. B. (2008). A Política de Atenção Integral à Saúde da Mulher: Uma análise de integralidade e gênero. SER Social, 10(22), 161-182. https://doi.org/10.26512/ser_social.v10i22.12950 
Souza, L. L., Peres, W. S., \& Araújo, D. B. (2015). Problematizações de gênero no campo da enfermagem: Diálogos com feminismos e a teoria queer. Revista NUPEM, 7(13), 121-142. https:// doi.org/10.33871/nupem.v7i13.274

Straub, R. O. (2014). Psicologia da saúde. ArtMed.

Toneli, M. J. F., Souza, M. G. C., \& Müller, R. C. F. (2010). Masculinidades e práticas de saúde: Retratos da experiência de pesquisa em Florianópolis/SC. Physis - Revista de Saúde Coletiva, 20(3), 973-994. https://doi.org/10.1590/ S0103-73312010000300015

Villela, W., Monteiro, S., \& Vargas, E. (2009). A incorporação de novos temas e saberes nos estudos em saúde coletiva: O caso do uso da categoria gênero. Ciência \& Saúde Coletiva, 14(4), 997-1006. https://doi.org/10.1590/ S1413-81232009000400002

\section{Juliana Machado Ruiz}

Residente multiprofissional em Reabilitação Física pela Faculdade de Medicina de São José do Rio Preto (Famerp). Mestre em Psicologia pelo Programa de Pós-Graduação em Psicologia da Universidade Federal do Triângulo Mineiro (UFTM), Uberaba - MG. Brasil.

E-mail: julianamruiz@hotmail.com

(1) https://orcid.org/0000-0002-0895-5253

Rafael De Tilio

Docente do Programa de Pós-Graduação e do Departamento de Psicologia da UFTM, Uberaba - MG. Brasil.

E-mail: rafaeldetilio.uftm@gmail.com

(1) https://orcid.org/0000-0002-4240-9707

Endereço para envio de correspondência:

Rua Siqueira Campos, 4380, casa 531. CEP: 13631-018. Pirassununga - SP. Brasil.

Recebido 19/08/2018

Aceito 30/09/2020

Received 08/19/2018

Approved 09/30/2020

Recibido 19/08/2018

Aceptado 30/09/2020

Como citar: Ruiz, J. M., \& De Tilio, R. (2021). Análise do discurso de gênero no contexto hospitalar: Perspectivas de mulheres internadas nas enfermarias de ginecologia e obstetrícia. Psicologia: Ciência e Profissão, 41, 1-15. https://doi.org/10.1590/1982-3703003212364

How to cite: Ruiz, J. M., \& De Tilio, R. (2021). Discourse analysis of gender in the hospital context: Perspectives of women hospitalized in gynecology and obstetrics wards. Psicologia: Ciência e Profissão, 41, 1-15.

https://doi.org/10.1590/1982-3703003212364

Cómo citar: Ruiz, J. M., \& De Tilio, R. (2021). Análisis del discurso de género en el contexto hospitalario: Perspectivas de mujeres internadas en las enfermerías de ginecología y obstetrician. Psicologia: Ciência e Profissão, 41, 1-15. https://doi.org/10.1590/1982-3703003212364 